\title{
A Novel control of a Grid-Interfacing Inverter to Improve the Quality of Power at PCC for a 3-Phase 4-wire DG System
}

\author{
V. Vijaya Lakshmi ${ }^{1}$, N.V. Vinay Kumar ${ }^{2}$, G.N.S. Vaibhav ${ }^{3}$. \\ ${ }^{1 .}$ PG Scholar [EPS], Dept. of EEE, PVKKIT, A.P, India. (Email: vijaya.lucky1@ gmail.com) \\ 2. Guide, Assistant professor, Dept. of EEE, PVKKIT, A.P, India. (Email: vinny255nanda@gmail.com) \\ ${ }^{3}$. HOD, Dept. of EEE, PVKKIT, A.P, India. (Email: vaibhavnaidu.naidu@gmail.com)
}

\begin{abstract}
:
Renewable energy resources (RES) are being increas- ingly connected in distribution systems utilizing power electronic converters. This paper presents a novel control strategy for achieving maximum benefits from these grid-interfacing inverters when installed in 3-phase 4-wire distribution systems. The inverter is controlled to perform as a multi-function device by incorporating active power filter functionality. The inverter can thus be utilized as: 1) power converter to inject power generated from RES to the grid, and 2) shunt APF to compensate current unbalance, load current harmonics, load reactive power demand and load neutral current. All of these functions may be accomplished either individually or simultaneously. With such a control, the combination of grid-interfacing inverter and the 3-phase 4-wire linear/non-linear unbalanced load at point of common coupling appears as balanced linear load to the grid. This new control concept is demonstrated with extensive MATLAB/Simulink simulation studies and validated through digital signal processor-based laboratory experimental results.

Index Terms: Active power filter (APF), distributed generation (DG), distribution system, grid interconnection, power quality (PQ), renewable energy.
\end{abstract}

\section{INTRODUCTION}

ELECTRIC utilities and end users of electric power are becoming increasingly concerned about meeting the growing energy demand. Seventy five percent of total global energy demand is supplied by the burning of fossil fuels. But increasing air pollution, global warming concerns, diminishing fossil fuels and their increasing cost have made it necessary to look towards renewable sources as a future energy solution. Since the past decade, there has been an enormous interest in many countries on renewable energy for power generation. The market liberalization and government's incentives have further accelerated the renewable energy sector growth. Renewable energy source (RES) integrated at distribution level is termed as distributed generation (DG). The utility is concerned due to the high penetration level of intermittent RES in distribution systems as it may pose a threat to network in terms of stability, voltage regulation and power-quality (PQ) issues. Therefore, the DG systems are required to comply with strict technical and regulatory frameworks to ensure safe, reliable and efficient operation of overall network.

With the advancement in power electronics and digital control technology, the DG systems can now be actively controlled to enhance the system operation with improved PQ at PCC. However, the extensive use of power electronics based equipment and non-linear loads at PCC generate harmonic currents, which may deteriorate the quality of power [1], [2].

Generally, current controlled voltage source inverters are used to interface the intermittent RES in distributed system. Recently, a few control strategies for grid connected inverters incorporating PQ solution have been proposed. In [3] an inverter operates as active inductor at a certain frequency to absorb the harmonic current. But the exact calculation of network inductance in real-time is difficult and may deteriorate the control performance. A similar approach in which a shunt active filter acts as active conductance to damp out the harmonics in distribution network is proposed in [4]. In [5], a control strategy for renewable interfacing inverter based on $p-q$ theory is proposed. In this strategy both load and inverter current sensing is required to compensate the load current harmonics.

The non-linear load current harmonics may result in voltage harmonics and can create a serious PQ problem in the power system network. Active power filters (APF) are extensively used to compensate the load current harmonics and load unbalance at distribution level. This results in an additional hardware cost. However, in this paper authors have incorporated the features of APF in the, conventional inverter interfacing renewable with the grid, without any additional hardware cost. Here, the main idea is the maximum utilization of inverter 
rating which is most of the time underutilized due to intermittent nature of RES. It is shown in this paper that the grid-interfacing inverter can effectively be utilized to perform following important functions: 1) transfer of active power harvested from the renewable resources (wind, solar, etc.); 2) load reactive power demand support; 3) current harmonics compensation at PCC; and 4) current unbalance and neutral current compensation in case of 3-phase 4-wire system. Moreover, with adequate control of grid-interfacing inverter, all the four objectives can be accomplished either individually or simultaneously. The PQ constraints at the PCC can therefore be strictly maintained within the utility standards without additional hardware cost.

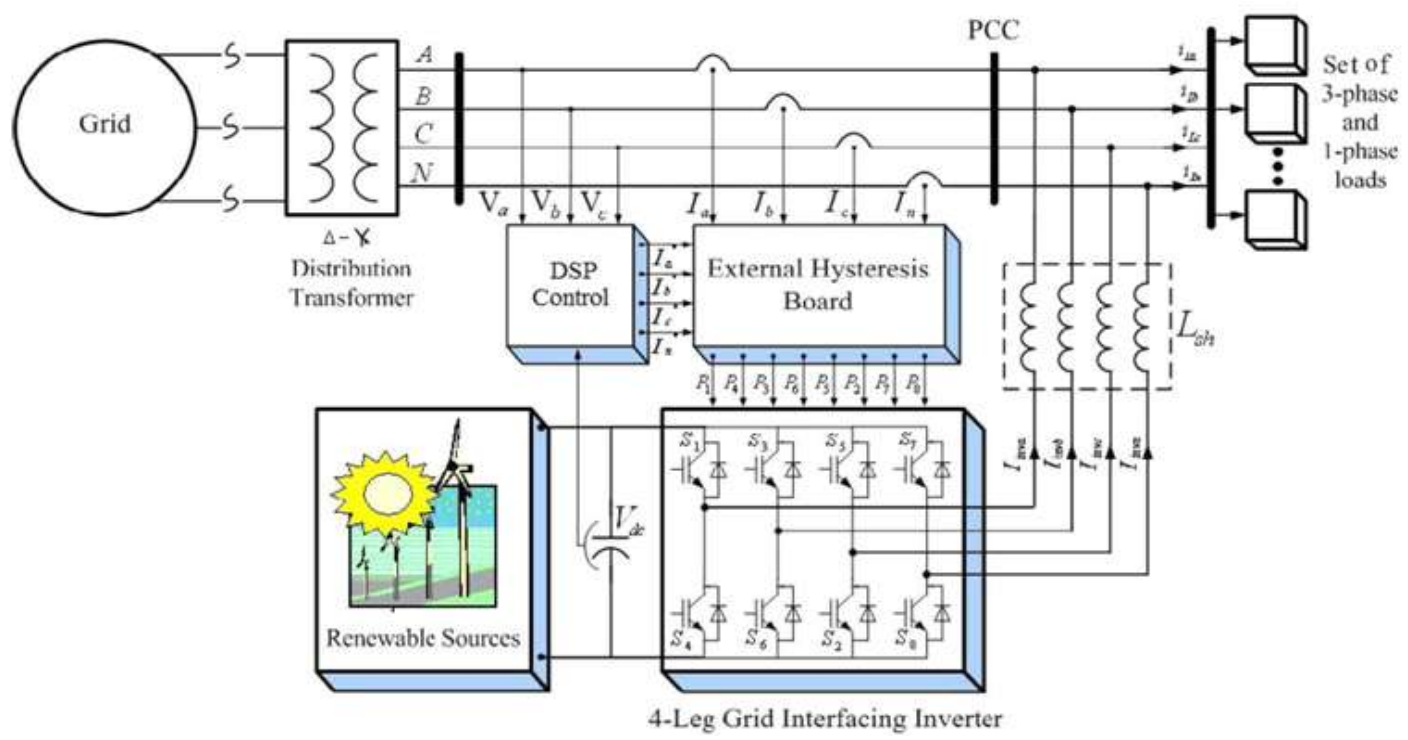

Fig. 1. Schematic of proposed renewable based distributed generation system.

The paper is arranged as follows: Section II describes the system under consideration and the controller for grid-in-terfacing inverter. A digital simulation study is presented in Section III. Extensive experimental results are discussed in Section IV and, finally, Section $\mathrm{V}$ concludes the paper.

\section{SYSTEM DESCRIPTION}

The proposed system consists of RES connected to the dc-link of a grid-interfacing inverter as shown in Fig. 1. The voltage source inverter is a key element of a DG system as it interfaces the renewable energy source to the grid and delivers the generated power. The RES may be a DC source or an AC source with rectifier coupled to dc-link. Usually, the fuel cell and photovoltaic energy sources generate power at variable low dc voltage, while the variable speed wind turbines generate power at variable ac voltage. Thus, the power generated from these renewable sources needs power conditioning (i.e., $\mathrm{dc} / \mathrm{dc}$ or $\mathrm{ac} / \mathrm{dc}$ ) before connecting on dc-link [6]-[8]. The dc-capacitor decouples the RES from grid and also allows independent control of converters on either side of dc-link.

\section{A. DC-Link Voltage and Power Control Operation}

Due to the intermittent nature of RES, the generated power is of variable nature. The dc-link plays an important role in trans-ferring this variable power from renewable energy source to the grid. RES are represented as current sources connected to the dc-link of a grid-interfacing inverter. Fig. 2 shows the systematic representation of power transfer from the renewable energy resources to the grid via the dc-link. The current injected by renewable into dc-link at voltage level $\gamma_{\square}$ can be given as

$$
I_{\mathrm{dcl}}=\frac{P_{\mathrm{fES}}}{V_{\mathrm{dc}}}
$$

where ${ }^{\mathrm{B}}$ Es is the power generated from RES 


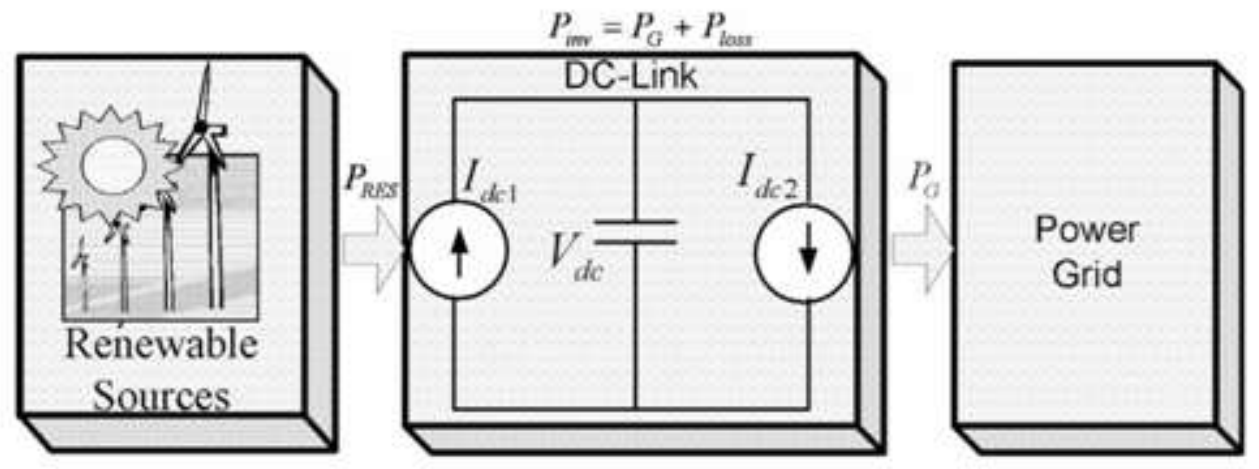

Fig. 2. DC-Link equivalent diagram.

The current flow on the other side of dc-link can be repre-sented as,

$$
I_{\mathrm{d} c 2}=\frac{P_{\mathrm{in}_{\mathrm{uv}}}}{V_{\mathrm{dc}}}=\frac{P_{G}+P_{\mathrm{L}_{\mathrm{gss}}}}{V_{\mathrm{dc}}}
$$

where $P_{\text {uv }} ?$ and 5 ase total power available at grid-in-terfacing inverter side, active power supplied to the grid and inverter losses, respectively. If inverter losses are negligible then ${ }^{\mathrm{B}} \mathrm{ES}=?$.

\section{B. Control of Grid Interfacing Inverter}

The control diagram of grid- interfacing inverter for a 3-phase 4-wire system is shown in Fig. 3. The fourth leg of inverter is used to compensate the neutral current of load. The main aim of proposed approach is to regulate the power at PCC during: 1) Prues_0; 2) Press totalload $P_{W}$ er $\left(\mathrm{PL}_{\mathrm{L}}\right)$; and 3) PuLs $>\mathrm{PL}$. While performing the power management operation, the inverter is actively controlled in such a way that it always draws/ supplies fundamental active power from/ to the grid. If the load connected to the PCC is non-linear or unbalanced or the combination of both, the given control approach also compensates the harmonics, unbalance, and neutral current.

The duty ratio of inverter switches are varied in a power cycle such that the combination of load and inverter injected power

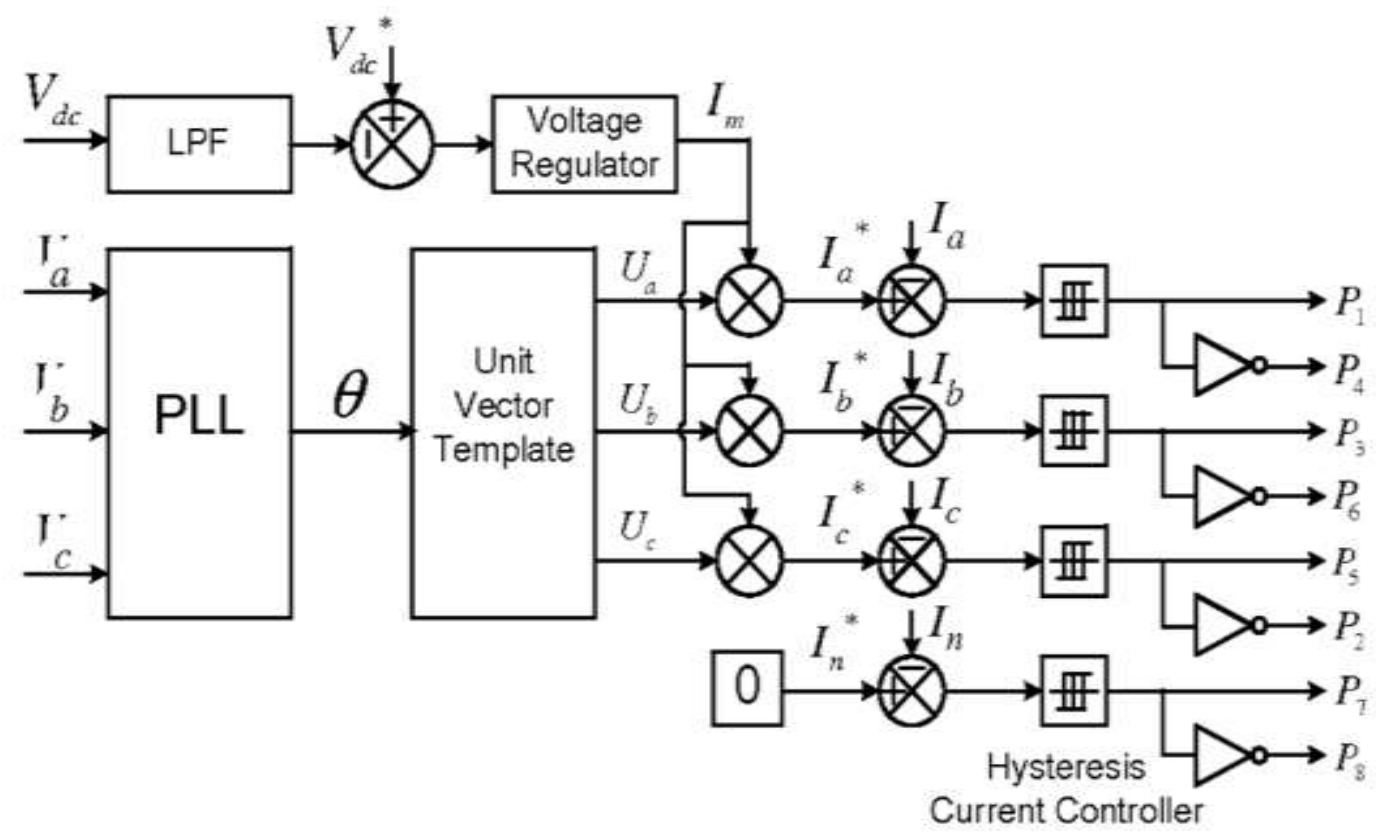

Fig. 3. Block diagram representation of grid-interfacing inverter control. 
appears as balanced resistive load to the grid. The regulation of dc-link voltage carries the information regarding the exchange of active power in between renewable source and grid. Thus the output of dc-link voltage regulator results in an active current $(F)$. The multiplication of active current component $\left(T^{\prime}\right)$ with unity grid voltage vector templates $(U E$, and $U$ ) generates the reference grid currents $\left(I_{*} I_{*}\right.$, and $\left.I_{*}\right)$. The reference grid neutral current $\left(I_{*}\right)$ is set to zero, being the instantaneous sum of balanced grid currents. The grid synchronizing angle $(\theta)$ obtained from phase locked loop (PLL) is used to generate unity vector template as [9]-[11]

$$
\begin{aligned}
& U_{a}=\operatorname{Sin}(\theta) \\
& U_{b}=\operatorname{Sin}\left(\theta-\frac{2 \pi}{3}\right) \\
& U_{c}=\operatorname{Sin}\left(\theta+\frac{2 \pi}{3}\right) .
\end{aligned}
$$

The actual dc-link voltage $\left(V_{\mathrm{dc}}\right)$ is sensed and passed through a first-order low pass filter (LPF) to eliminate the presence of switching ripples on the de-link voltage and in the generated reference current signals. The difference of this filtered do-link voltage and reference de-link voltage $(V$.$) is given to a discrete-$ PI regulator to maintain a constant dc-link voltage under varying generation and load conditions. The de-link voltage error ${ }^{d}$ at $n$th sampling instant is given as:

$$
V_{\mathrm{dcerr}(n)}=V_{\mathrm{dc}(n)}^{*}-V_{\mathrm{dc}(n)} .
$$

The output of discrete-PI regulator at $n$th sampling instant is expressed as

$$
I_{m(n)}=I_{m(n-1)}+K_{P V_{\text {den }}}\left(V_{\mathrm{d} c r \mathrm{rr}(n)}-V_{\mathrm{dccrr}(n-1)}\right)
$$

$$
+K_{I V_{\text {den }}} V_{\text {drerr }(n)}
$$

where $K r y d=10$ and $K_{Y d r}=0.05$ are proportional and integral gains of dc-voltage regulator. The instantaneous values of reference three phase grid currents are computed as

$$
\begin{aligned}
& I_{a}^{*}=I_{m} \cdot U_{a} \\
& I_{b}^{*}=I_{m} \cdot U_{b} \\
& I_{c}^{*}=I_{m} \cdot U_{c} .
\end{aligned}
$$

The neutral current, present if any, due to the loads connected to the neutral conductor should be compensated by forth leg of grid-interfacing inverter and thus should not be drawn from the grid. In other words, the reference current for the grid neutral current is considered as zero and can be expressed as

$$
I_{n}^{*}=0 .
$$

The reference grid currents $\left(I_{*}, I+I_{*}\right.$ and $\left.I_{*_{n}}\right)$ are compared with actual grid currents ( $T V T$ and 7 ) to compute the cur-rent errors as

$$
\begin{aligned}
& I_{\text {acrr }}=I_{a}^{*}-I_{a} \\
& I_{\text {berr }}=I_{b}^{*}-I_{b} \\
& I_{\text {cerr }}=I_{c}^{*}-I_{\sqsubset} \\
& I_{\text {nerr }}=I_{n}^{*}-I_{n} .
\end{aligned}
$$

These current errors are given to hysteresis current controller. The hysteresis controller then generates the switching pulses ( $P$ to ${ }^{\Gamma}$ ) for the gate drives of grid-interfacing inverter.

The average model of 4-leg inverter can be obtained by the following state space equations

$$
\begin{aligned}
& \frac{d I_{\mathrm{Inva}}}{d t}=\frac{\left(V_{\mathrm{Imva}}-V_{a}\right)}{L_{\mathrm{sh}}} \\
& \frac{d I_{\mathrm{I}^{\mathrm{nv}}}}{d t}=\frac{\left(V_{\mathrm{I}_{\mathrm{bv}}}-V_{b}\right)}{L_{\mathrm{sh}}}
\end{aligned}
$$

$$
\begin{aligned}
& d I_{\mathrm{I}} \quad\left(\begin{array}{ll}
V_{\mathrm{I}} & -V)
\end{array}\right. \\
& \frac{\text { nvc }}{d t}=\frac{\text { nve }}{L_{\mathrm{sh}}} \\
& d I_{\mathrm{I}} \quad\left(\begin{array}{ll}
V_{\mathrm{I}} & -V)
\end{array}\right. \\
& \frac{\text { nvn }}{d t}=\frac{\text { nyn } n}{L_{\mathrm{sh}}}
\end{aligned}
$$

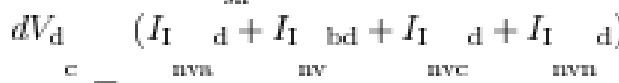

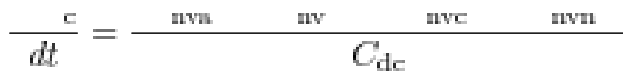

where $V_{\text {ua }} V_{\text {uvb }} V_{\text {uvc }}$, and $V_{\text {uvu }}$ are the three-phase ac switching voltages generated on the output terminal of inverter. These inverter output voltages can be modeled in terms of instantaneous dc bus voltage and switching pulses of the inverter as

$$
\begin{aligned}
& V_{\text {Inva }}=\frac{\left(P_{1}-P_{4}\right)}{2} V_{\mathrm{d} c} \\
& V_{\text {Inva }}=\frac{\left(P_{3}-P_{6}\right)}{2} V_{\mathrm{d} c} \\
& V_{\text {Inva }}=\frac{\left(P_{5}-P_{2}\right)}{2} V_{\mathrm{d} c} \\
& V_{\text {Inva }}=\frac{\left(P_{7}-P_{8}\right)}{2} V_{\mathrm{d} c} .
\end{aligned}
$$

Similarly the charging currents $\mathbb{V}_{\text {an }} \mathbb{V}^{\mathbb{a v p l d}} \mathbb{V}_{\text {avcd, }}$ and ${ }$ avul on dc bus due to the each leg of inverter can be expressed as 
ISSN : 2248-9622, Vol. 7, Issue 5, ( Part -4) May 2017, pp.49-59

$$
\begin{aligned}
& I_{\text {Invad }}=I_{\text {Inva }}\left(P_{1}-P_{4}\right) \\
& I_{\text {Invbd }}=I_{\text {Inub }}\left(P_{3}-P_{6}\right) \\
& I_{\text {Invcd }}=I_{\text {Invec }}\left(P_{5}-P_{2}\right) \\
& I_{\text {Invad }}=I_{\text {Inva }}\left(P_{7}-P_{8}\right) .
\end{aligned}
$$

$$
\begin{aligned}
& I_{\text {Inva }}<\left(I_{\text {Inva }}^{*}-h_{b}\right) \\
& \left(P_{1}=0\right) \\
& I_{\text {Inva }}>\left(I_{\text {Inva }}^{*}-h_{b}\right) \\
& \left(P_{1}=1\right)
\end{aligned}
$$$$
S_{4} \quad \begin{aligned}
& S_{1} \\
& \left(P_{4}=1\right)
\end{aligned}
$$$$
S_{4}
$$

the phase "a" leg of inverter.

where $h_{\text {if }}$ is the width of hysteresis band. On the same principle, the switching pulses for the other remaining three legs can be derived.

The switching pattern of each IGBT inside inverter can be for-mulated on the basis of error between actual and reference cur-

\section{SIMULATION RESULTS}

rent of inverter, which can be explained as:

If $\quad$, then upper switch

and lower switch

will be $\mathrm{ON}$

phase "a" leg of inverter.

If $\quad$, then upper switch and lower switch

will be OFF will be OFA hieve multi-objectives for grid interfaced DG systems connected to a 3-phase 4-wire network, an in thetensive simulation study is carried out using MATLAB/Simulink. A 4-leg current controlled voltage source inverter is actively controlled to achieve balanced sinusoidal grid currents at unity will be (Dwer factor (UPF) despite of highly unbalanced nipnlinear load at PCC under varying renewable generating conditions. A RES with variable output power is connected on the dc-link of grid-interfacing inverter. An unbalanced 3-phase 4-wire nonlinear load, whose unbalance, harmonics, and reactive power need to be compensated, is connected on PCC. The waveforms of

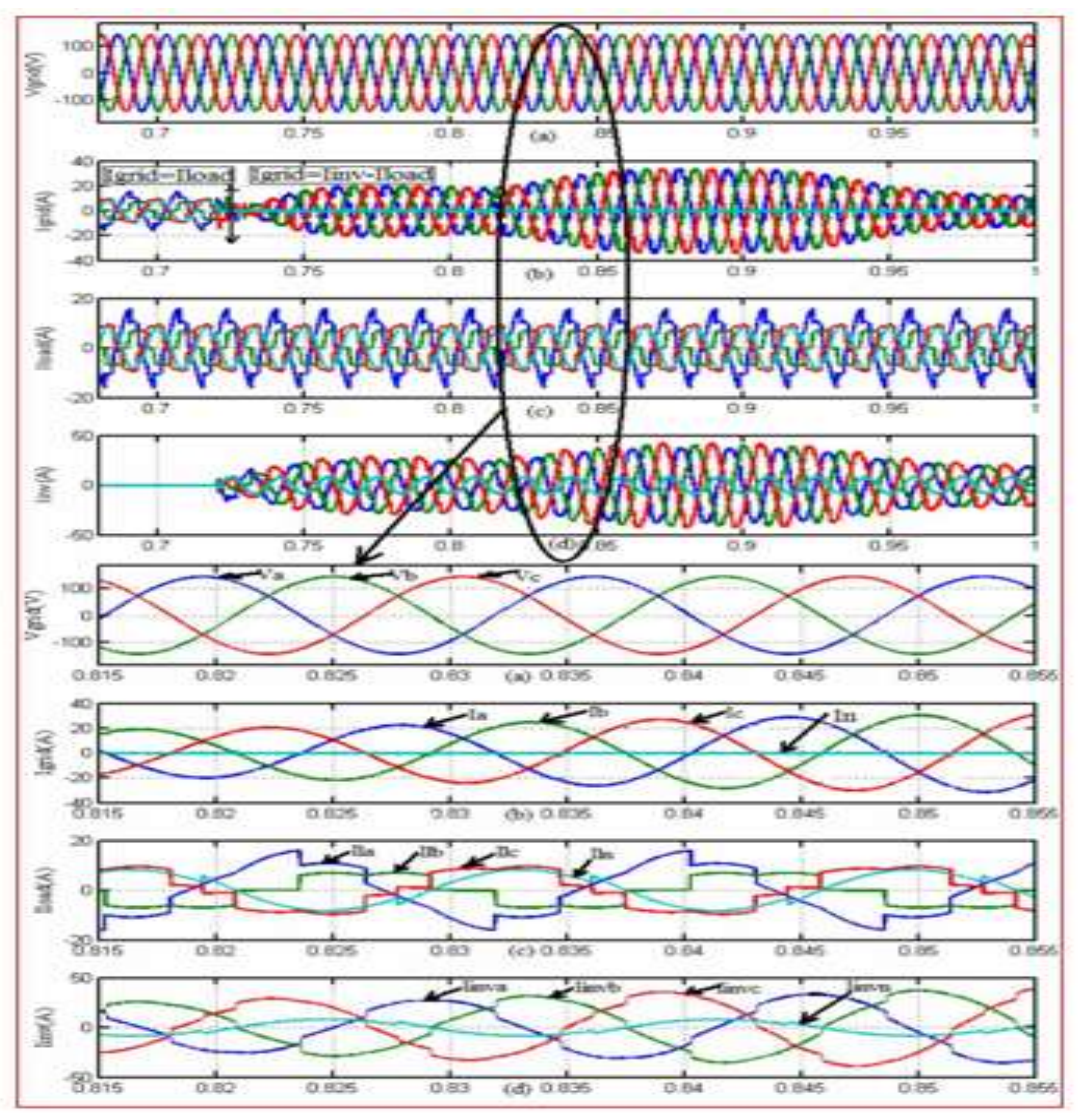

Fig. 4. Simulation results: (a) Grid voltages, (b) Grid Currents (c) Unbalanced load currents, (d) Inverter Currents. 
grid voltage $\left(V_{a}, V_{b, 9} V_{c}\right)$, grid currents $\left(I_{a,}, I_{b, n} I_{c,}, I_{n}\right)$, un- Initially, the grid-interfacing inverter is not balanced load current ( $I_{\mathrm{la}}, I_{\mathrm{lb}} I_{\mathrm{l},}$, Iand inverter currenosnected to the network (i.e., the load power ( $\left.I_{\text {inva }}, I_{\text {invb }}, I_{\text {inve, }} I_{\text {invu }}\right)$ are shown in Fig. 4 . The cordemand is totally supplied by the grid alone). sponding active-reactive powers of grid $\left(P_{\mathrm{gr} \text { rid }}, Q_{\mathrm{gr} \text { rid }}\right)$, ldaherefore, before time $\mathrm{t}=0.72 \mathrm{~s}$, the grid cur-rent ( $P_{\text {load }}, Q$ and)inverter $\quad\left(P_{\text {linv }}, Q_{\text {inv }}\right)$ are shown in Figp5ofile in Fig. 4(b) is identical to the load current profile of Fig. 4(c). At $t=0.72 \mathrm{~s}$, the grid-interfacing

Positive values of grid active-reactive powers and inverter active-reactive powers imply that these powers flow from grid side towards PCC and from inverter towards PCC, respectively. The active and reactive powers absorbed by the load are denoted by positive signs. inverter is connected to the network. At this instant the inverter starts injecting the current in such a way that the profile of grid current starts changing from unbalanced non linear to balanced sinusoidal current as shown in Fig. 4(b). As the inverter also supplies the
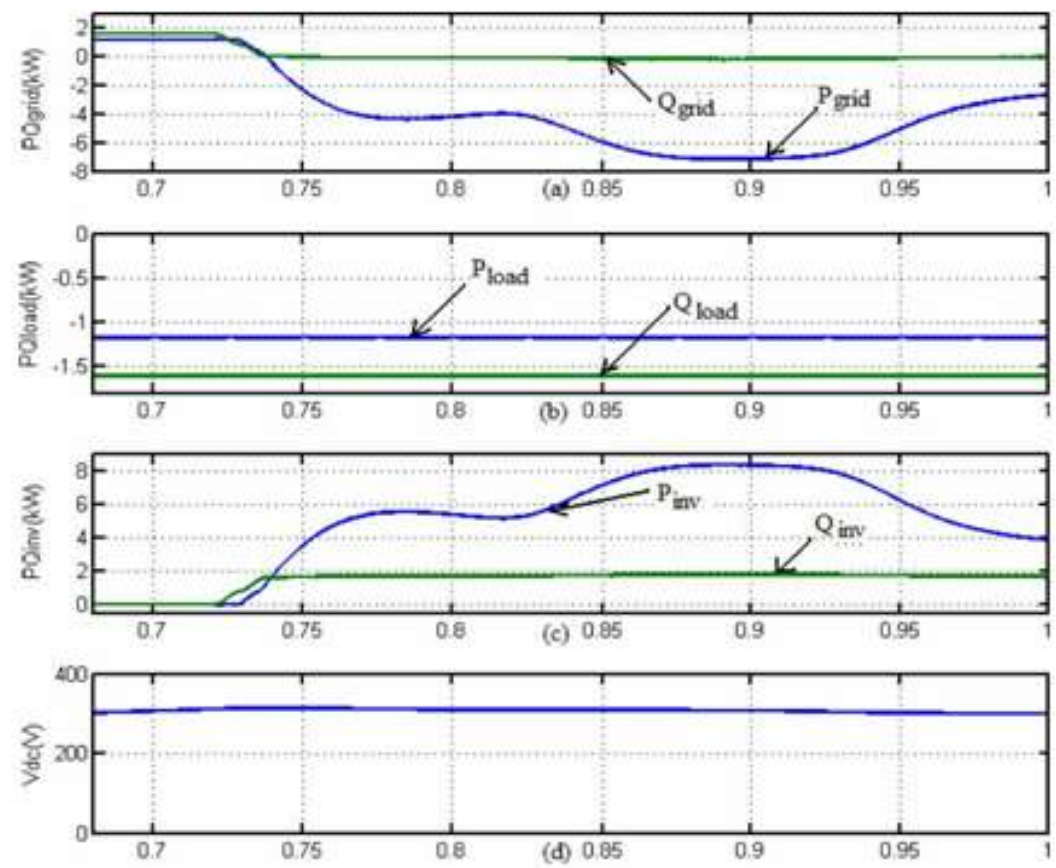

Fig. 5.Simulation results: (a) PQ-Grid, (b) PQ-Load, (c) PQ-Inverter, (d) dc-link voltage.

towards grid, which can be noticed from the

load neutral current demand, the grid neutral current $\left(I_{n}\right)$ baereased magnitude of grid cur-rent as indicated by comes zero after $\mathrm{t}=8.72$ its profile. At $t=0.92 \mathrm{~s}$, the power available from At $\mathrm{t}=0.72 \mathrm{~s}$, the inverter starts injecting active power gdRES is reduced. The corresponding change in the erated from RES $\left(P_{\mathrm{RES}} \approx P_{\text {inv }}\right)$. Since the generated powerimserter and grid currents can be seen from Fig. 4. The active and re-active power flows between the

more than the load power demand the additional power is fed back to the grid. The negative sign of $P$ rill, after time 0.72 s suggests that the grid is now receiving power from RES. More-over, the gridinterfacing inverter also supplies the load reactive power demand locally. Thus, once the inverter is in operation the grid only supplies/receives fundamental active power.

At $t=0.82 \mathrm{~s}$, the active power from RES is increased to evaluate the performance of system under variable power gener-ation from RES. This results in increased magnitude of inverter current. As the load power demand is considered as constant, this additional power generated from RES flows inverter, load and grid during increase and decrease of energy generation from RES can be noticed from Fig. 5. The dc-link voltage across the grid- interfacing inverter (Fig. 5(d)) during different operating condition is maintained at constant level in order to facilitate the active and reactive power flow. Thus from the simulation results, it is evident that the grid-interfacing inverter can be effectively used to compensate the load reactive power, current unbalance and cur-rent harmonics in addition to active power injection from RES. This enables the grid to supply/ receive sinusoidal and balanced power at UPF. 


\section{EXPERIMENTAL VALIDATION}

The performance of the proposed control approach is vali-dated with the help of a scaled laboratory prototype that has system parameters as given in Table I. The RES is emulated

Table I: System Parameter

$\begin{array}{ll}\text { 3-phase Supply (r.m.s.) } & : V_{g}=30 \mathrm{~V}, 60 \mathrm{~Hz} \\ \text { 3-phase Non-linear Load } & : R=26.66 \Omega, L=10 \mathrm{mH} \\ \text { 1-phase Linear Load (A-N) } & : R=36.66 \Omega, L=10 \mathrm{mH} \\ \text { 1-phase Non-Linear Load (C-N) : } R=26.66 \Omega, L=10 \mathrm{mH} \\ \text { DC-Link Capacitance \& Voltage: } C_{d c}=3000 \mu F, V_{d c}=90 \mathrm{~V} \\ \text { Coupling Inductance } & : L_{s h}=2.0 \mathrm{mH}\end{array}$

using an auxiliary controlled converter, which injects varying active power at the dc-link of an insulated gate bipolar transistor (IGBT) based 4-leg voltage source inverter connected to grid. A 3-phase 4-wire nonlinear load, composed of 3-phase nonlinear balanced load, 1-phase R-L load between phase $a$ and neutral and 1-phase non-linear load between phase $E$ and neutral, is con-nected to the grid. The total harmonics distortions (THDs) of phase $a b$ and $c$ load currents are noticed as $14.21 \%$, $22.93 \%$; and $16.21 \%$, respectively. The DS $1104{ }^{\circledR}$ DSP of dSPACE is utilized to generate the reference grid current signals in real-time. The difference of reference and actual grid current signals is applied to external hysteresis board to generate the gate pulses for IGBT's. The proposed control approach requires a sampling time of $75 \mu^{\mu} \mathrm{s}$ to execute the MATLAB/Simulink generated C-codes in real-time.

The experimental results are divided into three different modes of operation in order to highlight the validity of pro-posed controller. First mode of operation considers a situation when there is no power generation from RES. Under such condition, the grid-interfacing inverter is utilized as shunt APF to enhance the quality of power at PCC. While in second mode of operation, the inverter injects RES active power into grid and also incorporates the active power filtering functionality. In the third mode, the dynamic operation of proposed controller is examined. The experimental results are given in Figs. 6-10. All the voltage and current waveforms are captured utilizing an oscilloscope, whereas, the active and reactive powers are captured in real-time using Control Desk Developer environment.

\section{A. Mode of Operation-PQ Enhancement $\left(\mathrm{PrE}_{\mathrm{L}}=0\right)$}

Fig. 6 shows the experimental results for active power fil-tering mode of operation when there is no power generation from RES. All the current waveforms are shown with respective to grid side phase $a$ voltage $(V)$. Fig. 6(a) shows the profile of the unbalance non-linear load currents. The grid current pro-file, when grid-interfacing inverter controlled as shunt APF, is shown in Fig. 6(b). It can be noticed that the highly unbalanced load currents, after compensation, appear as pure sinusoidal balanced set of currents on grid side. The grid current THD's are reduced to $2.36 \%, 1.68 \%$, $3.65 \%$ for $a b$ and $c$ phases, respectively. In Fig. 6(c), the compensating inverter currents are shown for each phase along with dc-link voltage. For the experimental study, the dc-link voltage is maintained at $100 \mathrm{~V}$. Fig. 6(d) shows the traces for neutral current of grid, load and inverter. The load neutral current due to single-phase loads is effectively compensated by the 4th leg of inverter such that the current in grid side neutral conductor is reduced to zero. 


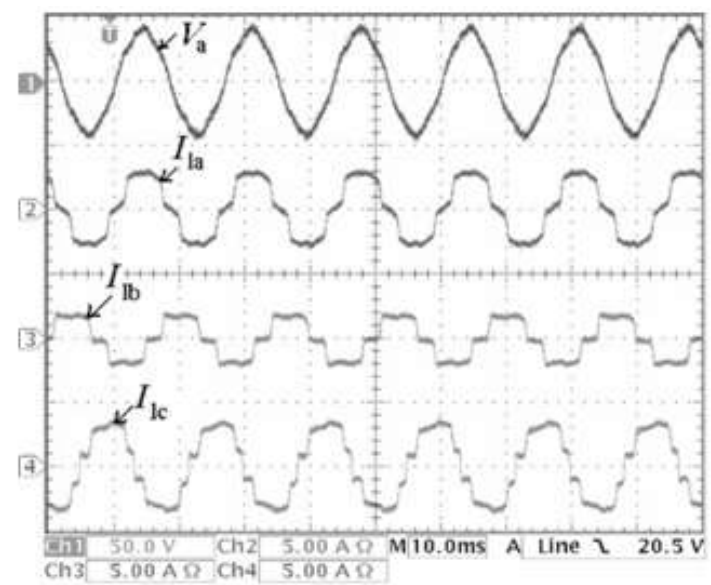

(a)

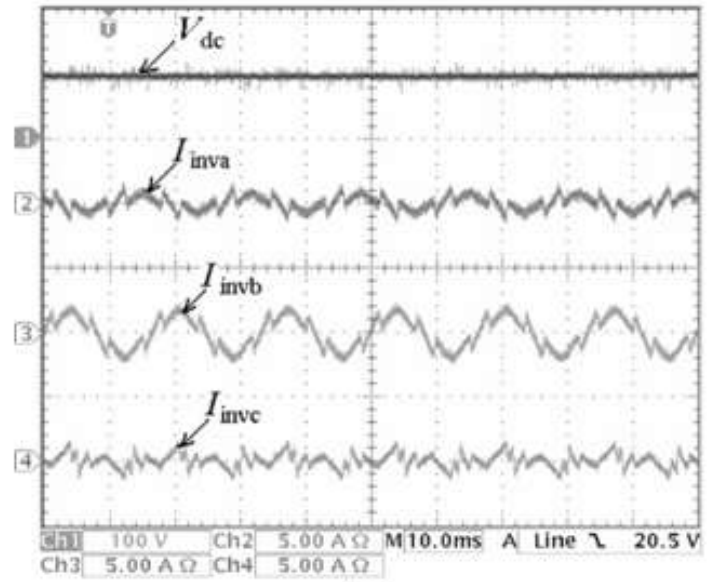

(c)

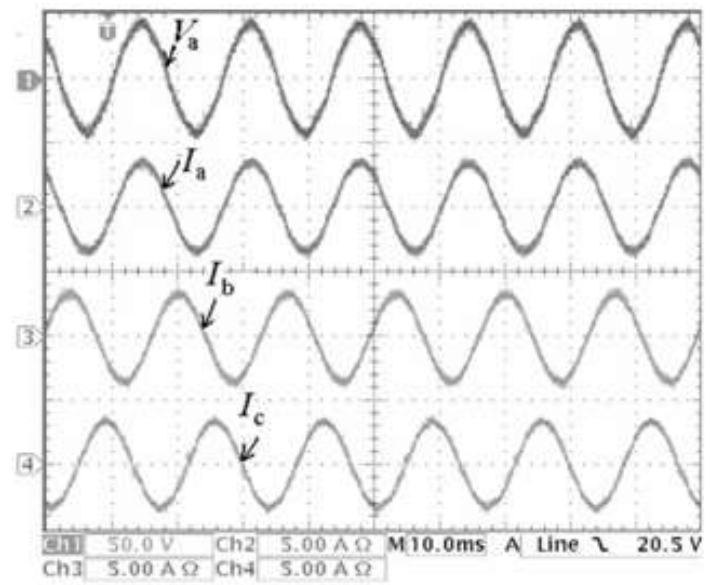

(b)

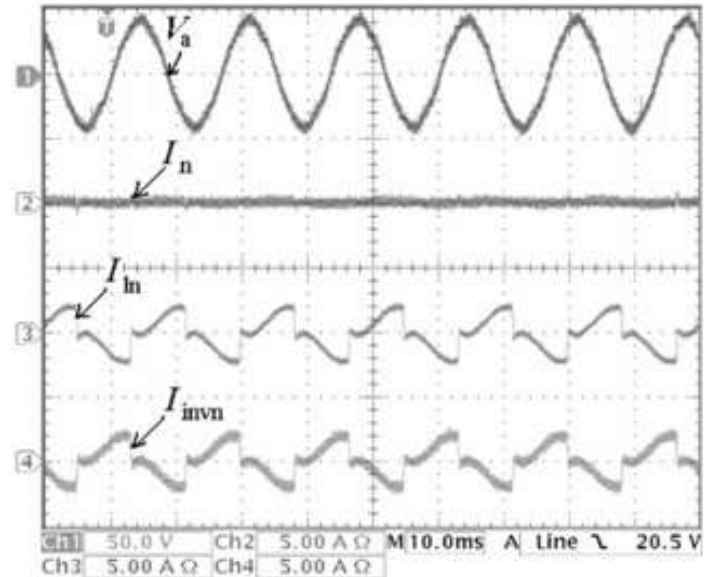

(d)

Fig. 6. Experimental results for the active power filtering mode nu : (a) unbalanced load currents, (b) grid currents after compensation, (c) currents injected by grid-interfacing inverter, (d) load, grid and inverter neutral currents.
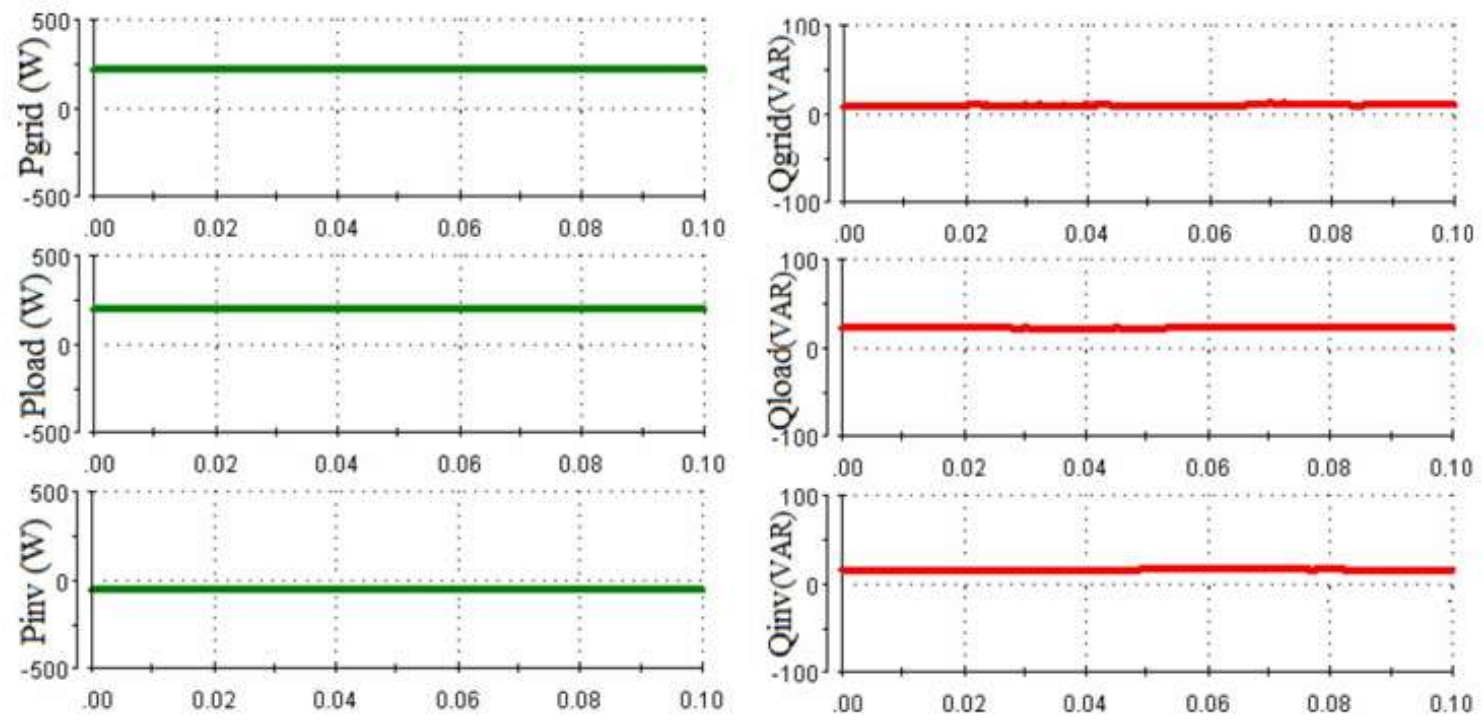

Fig. 7. Experimental results for the active power filtering mode $\quad$ : active and reactive power flow in real-tim 


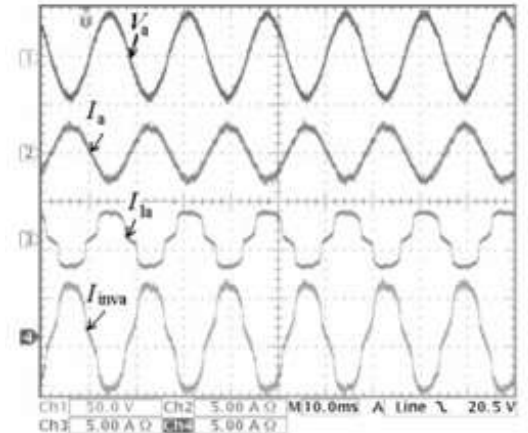

(a)

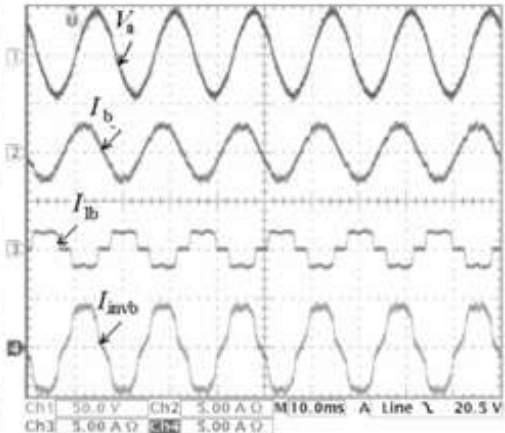

(b)

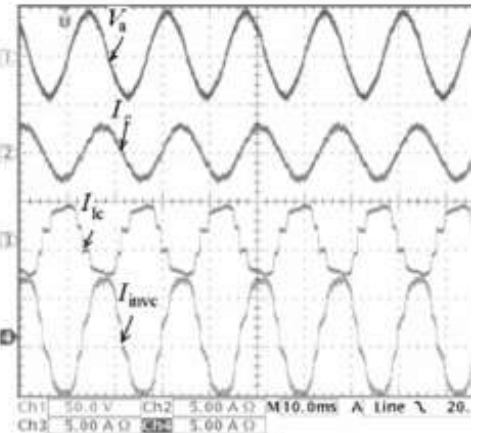

(c)

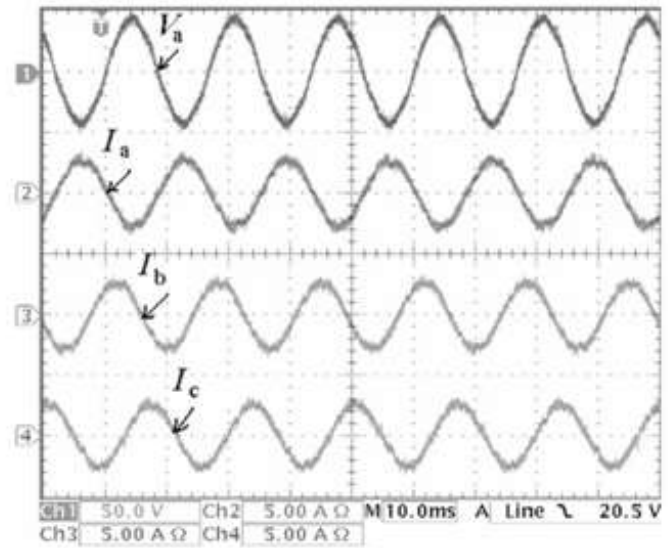

(d)

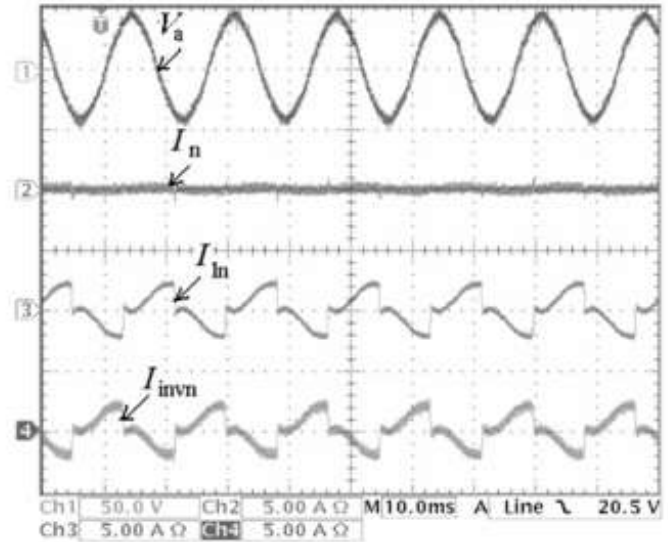

(e)

Fig. 8. Experimental results for the active power filtering and renewable power injection mode ( $\left.P_{m}>P_{\mathbf{L}}\right)$ : (a) phase a performance, (b) phase performance,

(c) phase performance, (d) grid currents (e) load, grid and inverter neutral currents.

Fig. 7 shows the total active and reactive powers of grid, load and inverter. In the APF mode of operation, the inverter con-sumes a small amount of active power to maintain the dc-link voltage and to overcome the losses associated with inverter, while most of the load reactive power need is supported by in-verter effectively. Thus, this mode of operation validates the concept of utilization of gridinterfacing inverter as shunt APF when there is no power generation from the RES. The experi-mental results demonstrate the effective compensations of load current unbalance, harmonics and reactive power.

\section{B. Mode of Operation-Simultaneous $P Q$ Enhancement and}

RES Power Injection (PILs $>\mathrm{P}_{\mathrm{L}}$ )

The experimental results for simultaneous active power fil-tering and RES power injection mode are shown in Fig. 8. In this case study it is considered that the generated power at grid-in-terfacing inverter is more than the total load power demand. Therefore, after meeting the load power demand, the additional RES power flows towards grid. The profiles of grid, load and inverter currents for individual phases are shown in Figs. 8(a), (b) \& (c) for phase $a b$ and $c$, respectively. As noticed from Fig. 8(a) to (c), the inverter currents consist of two components: 1) steady-state load current component and 2) grid active power injection component. Thus the grid-interfacing inverter now provides the entire load power demand (active, reactive and harmonics) locally and feeds the additional active power (sinusoidal and balanced) to the grid. The exact out-of phase relationship between phase $\longrightarrow$ grid voltage and phase $\longrightarrow$ grid current suggests that this additional power is fed to the grid at UPF. The three-phase grid currents (Fig. $8(d)$ ) suggest that the injected active power from RES to the grid is supplied as bal-anced active power even the load on the system is unbalanced in nature. During both mode of operation, as the load on the system is considered constant, the load neutral current profile and its compensation is identical to the one already discussed in previous subsection and can also be noticed from Figs. 6(d) and $8(\mathrm{e})$.

The exchange of total active and reactive powers between grid, load and inverter are shown in Fig. 9. The negative sign of total grid side active power demonstrates that the excess power generated by 
RES flows towards grid side. Thus, this case study demonstrates that the grid-interfacing inverter can simultane-ously be utilized to inject power generated from RES to PCC and to improve the
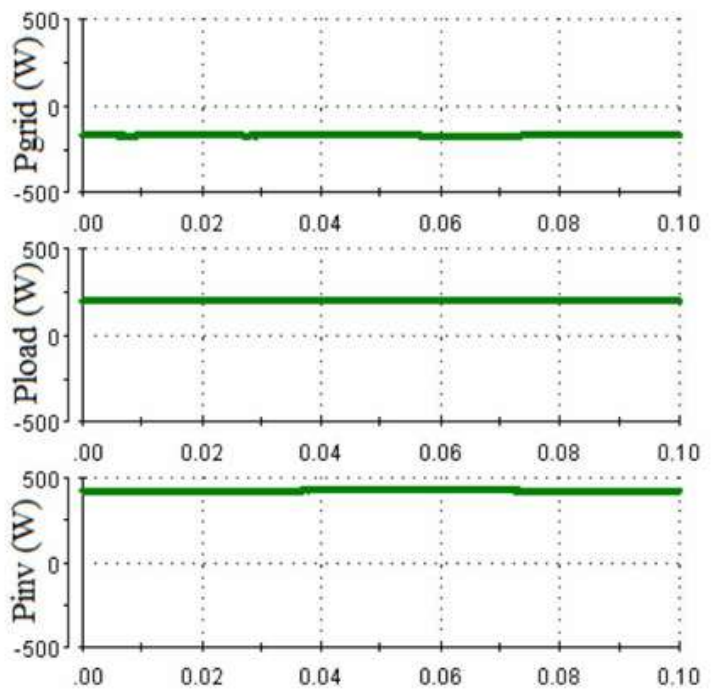

quality of power (current unbalance compensa-tion, current harmonics compensation, load reactive power sup-port, neutral current compensation) at PCC.
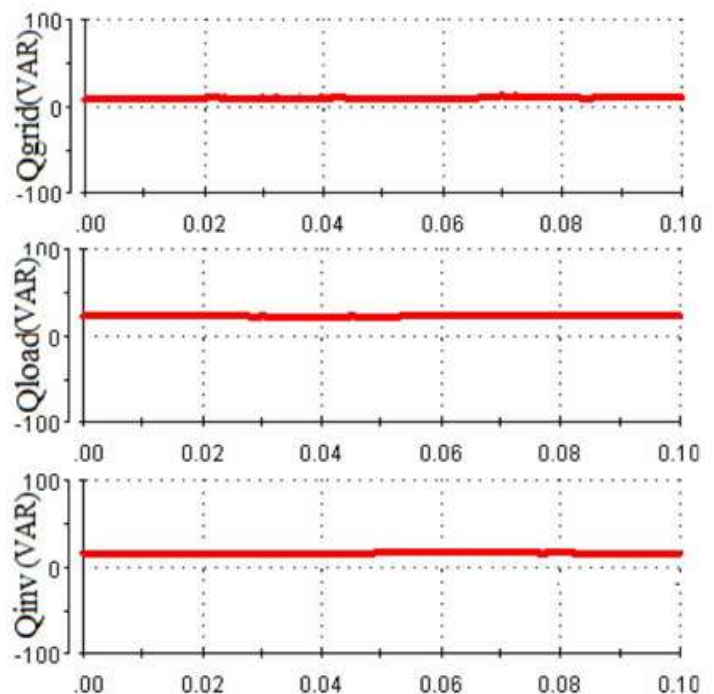

Fig. 9. Experimental results for the active power filtering and renewable power injection mode nar : active and reactive power flow in real time.

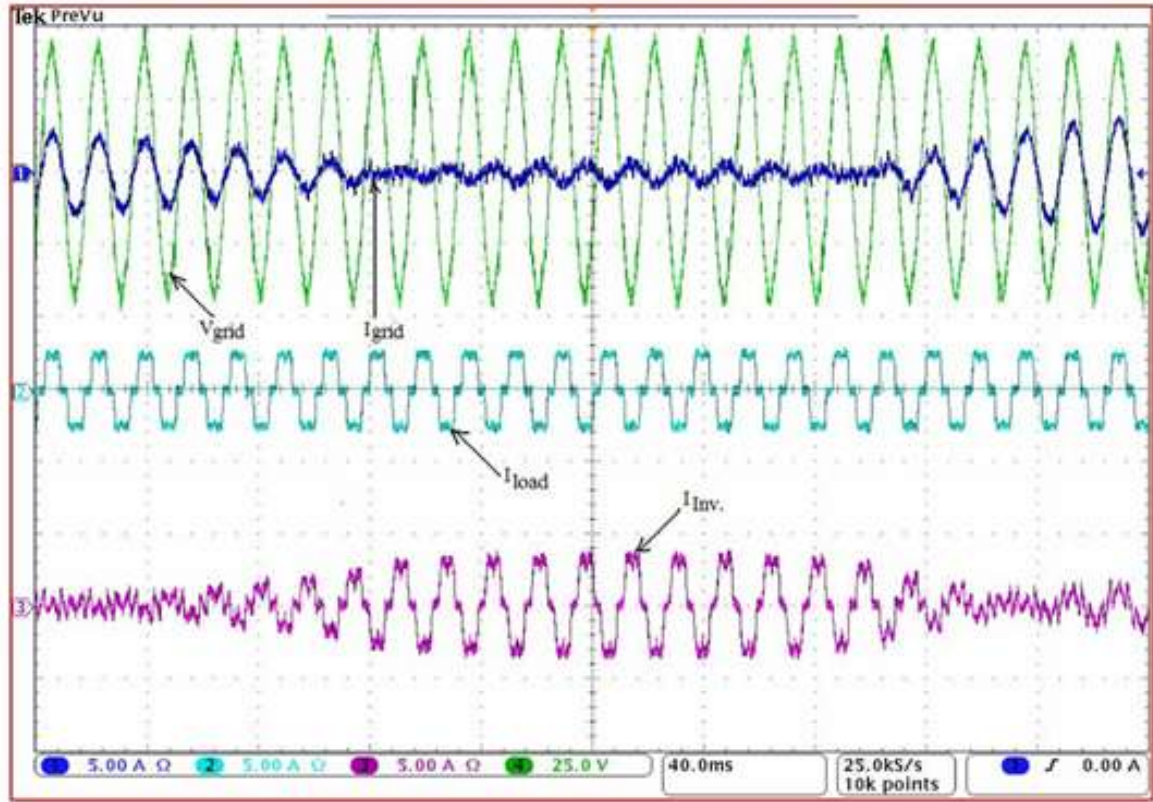

Fig. 10. Experimental results: Dynamic performance of proposed approach.

\section{Dynamic Performance of Proposed Control Approach}

Fig. 10 shows the experimental results to validate the dynamic performance of proposed control approach under different modes of operation. Initially, it is considered that the system is working under mode-A operating condition (i.e., non-linear load current harmonics and reactive power compensation). After few cycles, the power at dc-link is initially increased and then decreased, which can be noticed from the amplitude of injected inverter current profile. The corresponding decrease (for increased power level at dc-link) and increase (for decreased power level at dc-link) in grid current magnitude can also be noticed from Fig. 10, under constant load conditions. Thus, the proposed controller precisely manages any variation in real power at dc-link and effectively feeds it to the main grid. A smooth changeover from modeA operating condition to the mode-B can be noticed from Fig. 10. 


\section{CONCLUSION}

This paper has presented a novel control of an existing grid-interfacing inverter to improve the quality of power at PCC for a 3-phase 4-wire DG system. It has been shown that the grid-interfacing inverter can be effectively utilized for power conditioning without affecting its normal operation of real power transfer. The grid-interfacing inverter with the proposed approach can be utilized to:

i) inject real power generated from RES to the grid, and/or,

ii) operate as a shunt Active Power Filter (APF).

This approach thus eliminates the need for additional power conditioning equipment to improve the quality of power at PCC. Extensive MATLAB/Simulink simulation as well as the DSP based experimental results have validated the proposed approach and have shown that the gridinterfacing inverter can be utilized as a multifunction device.

It is further demonstrated that the PQ enhancement can be achieved under three different scenarios: 1) Pres=0, 2)

Press $<$ Pload, and 3) Press $>$ Pload. The current unbalance, current harmonics and load reactive power, due to unbalanced and non-linear load connected to the PCC, are compensated effectively such that the grid side currents are always maintained as balanced and sinusoidal at unity power factor. Moreover, the load neutral current is prevented from flowing into the grid side by compensating it locally from the fourth leg of inverter. When the power generated from RES is more than the total load power demand, the grid-interfacing inverter with the proposed control approach not only fulfills the total load active and reactive power demand (with harmonic compensation) but also delivers the excess generated sinusoidal active power to the grid at unity power factor.

\section{REFERENCES}

[1]. J. M. Guerrero, L. G. de Vicuna, J. Matas, M. Castilla, and J. Miret, "A wireless controller to enhance dynamic performance of parallel in-verters in distributed generation systems," IEEE Trans. Power Elec-tron., vol. 19, no. 5, pp. 1205-1213, Sep. 2004.

[2]. J. H. R. Enslin and P. J. M. Heskes, "Harmonic interaction between a large number of distributed power inverters and the distribution net-work," IEEE Trans. Power Electron., vol. 19, no. 6, pp. 15861593, Nov. 2004.
[3]. U. Borup, F. Blaabjerg, and P. N. Enjeti, "Sharing of nonlinear load in parallelconnected three-phase converters," IEEE Trans. Ind. Appl., vol. 37, no. 6, pp. 18171823, Nov./Dec. 2001.

[4]. P. Jintakosonwit, H. Fujita, H. Akagi, and S. Ogasawara, "Implemen-tation and performance of cooperative control of shunt active filters for harmonic damping throughout a power distribution system," IEEE Trans. Ind. Appl., vol. 39, no. 2, pp. 556-564, Mar./Apr. 2003.

[5]. J. P. Pinto, R. Pregitzer, L. F. C. Monteiro, and J. L. Afonso, "3-phase 4-wire shunt active power filter with renewable energy interface," pre-sented at the Conf. IEEE Rnewable Energy \& Power Quality, Seville, Spain, 2007.

[6]. F. Blaabjerg, R. Teodorescu, M. Liserre, and A. V. Timbus, "Overview of control and grid synchronization for distributed power generation systems," IEEE Trans. Ind. Electron., vol. 53, no. 5, pp. 1398-1409, Oct. 2006.

[7]. J. M. Carrasco, L. G. Franquelo, J. T. Bialasiewicz, E. Galván, R. C.P. Guisado, M. Á. M. Prats, J. I. León, and N. M. Alfonso, "Power- electronic systems for the grid integration of renewable energy sources: A survey," IEEE Trans. Ind. Electron., vol. 53, no. 4, pp. 1002-1016, Aug. 2006.

[8]. B. Renders, K. De Gusseme, W. R. Ryckaert, K. Stockman, L. Van- develde, and M. H. J. Bollen, "Distributed generation for mitigating voltage dips in low-voltage distribution grids," IEEE Trans. Power. Del., vol. 23, no. 3, pp. 1581-1588, Jul. 2008.

[9]. V. Khadkikar, A. Chandra, A. O. Barry, and T. D. Nguyen, "Appli- cation of UPQC to protect a sensitive load on a polluted distribution network," in Proc. Annu. Conf. IEEE Power Eng. Soc. Gen. Meeting, 2006, pp. 867-872.

[10]. M. Singh and A. Chandra, "Power maximization and voltage sag/swell ridethrough capability of PMSG based variable speed wind energy conversion system," in Proc. IEEE 34th Annu. Conf. Indus. Electron. Soc., 2008, pp. 2206-2211.

[11]. P. Rodríguez, J. Pou, J. Bergas, J. I. Candela, R. P. Burgos, and D. Boroyevich, "Decoupled double synchronous reference frame PLL for power converters control," IEEE Trans. Power Electron, vol. 22, no. 2, pp. 584-592, Mar. 2007. 